\title{
Publicistički diskurs A.G. Matoša - od stila do političkog imaginarija
}

\begin{abstract}
Beck Boris, Publicistički diskurs A. G. Matoša-od stila do političkog imaginarija (Journalistic Discours of A.G. Matoš - from Style to Political Imagery). „Poznańskie Studia Slawistyczne" 7. Poznań 2014. Publishing House Science and Innovate, pp. 37-48. ISBN 978-83-63795-79-5. ISSN 2084-3011.
\end{abstract}

In the newspaper articles and feuilltons, Antun Gustav Matoš uses a variety of procedures analogous to his artistic creation and develops a rich figuration and characteristic irony. The journalistic discourse constructed in that way consistently creates political and social imaginary which confirms oppositions: nationally/internationally, individual/collective, tradition/ modernity and Croat/Serb, where the author clearly states his preference. Although Matoš consistently promote Starčević's heritage, liberalism and individualism, he does not simply convey a political message, but adds meaning to agitation, which boosts its suggestivness, but also causes that it becomes relative.

Keywords: figuration; irony; political imaginary; liberalism; revolution; nation; body

\section{Uvod}

Antun Gustav Matoš (1873.-1914.) smatra se „središnjom figurom hrvatske književnosti na prijelazu 19. i 20. stoljeća” prvenstveno zbog „cizeliranih soneta, predavangardne poeme Mòra, impresionističkih putopisa i simbolističke proze" (Oraić Tolić 2013: 15). U ovom će se radu prikazati neke stilske osobine njegovih publicističkih tekstova koji su također napisani na najvišoj razini, kako kaže Krešimir Nemec: „kod pravih umjetnika, a to je Matoš nesumnjivo bio, ideologija nikada ne guta književnost" (Nemec 2007: 129). Publicistika se pritom smatra „tiskanim materijalom 
aktualnoga kulturnog, književnog i društveno-političkog života u dnevnim i periodičnim listovima, časopisima i zasebnim listovima" (Silić 2006: 75), a što se Matoševih publicističkih žanrova tiče, pretežu kozerije, pamfleti, ogledi i parodije - ukratko, žanrovi ,propagandnoga, agitativnoga i zabavnoga karaktera” (Silić 2006: 80) koje odlikuje ,individualnost, subjektivnost, emocionalnost, figurativnost i ekspresivnost" (Silić 2006: 81).

Ideologija se pak može shvatiti kao ,temelj društvene reprezentacije koju dijele članovi iste grupe" (van Dijk 1998: 8), a u Matoševu slučaju riječ je o pravaškom svjetonazoru, kako je već opsežno prikazano u znanstvenoj literaturi (Nemec 2007; Jonjić 2012; Oraić Tolić 2013). On je veći dio života proveo u egzilu i nepovoljnim materijalnim prilikama, suočavajući se s cenzurom, pritiscima i kompromisima - zbog čega su za ocjenu njegovih političkih i društvenih pogleda ključne zadnje godine života kada ,piše kao - uvjetno rečeno - slobodan čovjek" (Jonjić 2012: 19). No i prije tih godina kakve-takve slobode u svim je Matoševim tekstovima očito izrazito nastojanje da bude neovisan, pa čak i „u odnosu na stranku kojoj je pripadao” (Jonjić 2012: 19). Matoš se načelno zalaže za samostalnu hrvatsku državu oslobođenu od austrijske, mađarske i talijanske hegemonije, a suprotstavlja se i jugoslavenskim tendencijama, sve to uz naglašeni antiklerikalizam.

\section{Pravaštvo, liberalizam, revolucija}

Figurativnost kao odlika Matoševe umjetničke proze istaknuta je u studiji Krunoslava Pranjića na razini igara riječima (1971: 49 i dalje), ironije (1971: 136) i metafore (1971: 181 i dalje). Osim tih figura uočljivo je kod Matoša bogatstvo sinonimnih izraza pa tako, primjerice, pišući o tada aktualnoj temi trebaju li žene nositi hlače (Dimije 1911; Matoš 1973c: 19-21), navodi čak osam sinonima (, „̌akšire, gaće, gege, hlače, joupe-culottes, pantalone, pelen-gaće”) i još osam izraza iz istoga semantičkog polja (,hozntregeri, toaleta, suknja, svila, šlep, šnajderija, švimhozne, žipon"). Budući da je Matoš protivan tome da žene nose hlače, može se zaključiti da je i toliko obilje bliskoznačnica u funkciji ironizacije.

„Gomilanje značenjski bliskih pojedinosti” obilježje je figure akumulacije (Bagić 2012: 14) koju Matoš na više mjesta koristi autoironično. Primjerice, svoj društveni položaj omalovažava kada piše da je „poklisar hrvatski” 
u Parizu imao u Matošu ,tek jednog jedinog pomagača, sekretara i lizača cipela, pisara i prepisivača, lakaja i poslaničkog savjetnika" (Impromtu. Op. II. Pismo iz Afrike 1904; Matoš 1973b: 15), a slično je i kad tematizira svoju oskudicu: „Kišobran ne nosim iz principa, ogrtač mi bijaše odnesen u zalogu, zimski kaput ne htjedoh navući zbog mode, a jesenji vjetar i kišica šibahu prozore moje sobice" (Nikad više! Feljton 1895; Matoš 1973b: 7).

Deprecijaciju sebe Matoš iskazuje i sljedećom katahrezom: „A.G. Matoš, taj njegov Mädchen für Alles" (Impromtu. Op. II. Pismo iz Afrike 1904; Matoš 1973b: 15). Izraz „djevojka za sve” postoji, naime, samo u varijanti ženskog roda, tako da identificiranje osobe muškog spola (Matoša) s pojavom ženskog roda ironiju pojačava do grotesknosti. Uz katahrezu, kao figuru koja spaja nespojivo (cf. Bagić 2012: 171-173), Matoš koristi i prozopopeju, krajnji oblik personifikacije (cf. Bagić 2012: 268), kada sebe imenuje mrtvim te kao mrtvac govori o politici i još k tome mrtvim proglašava bana: „Mojom smrću izgubi tvoja domovina najvećeg don Ivana. No, kako je naša vlada praktična, znala me je upotrijebiti i iza smrti. Nj. Preuzvišenost Khuen Héderváry, bog mu duši lako" (Pismo iz Pariza 1904; Matoš 1973b: 15).

Proglašavanje živog čovjeka mrtvim sarkazam je koji predstavlja simbolično ubojstvo, a hrvatski ban Károly Khuen-Héderváry jamačno je bio prvi na pravaškoj ,listi za odstrel”. Ironija je ovdje dvostruka: prvo se verbalno upokojeni ban naziva Njegovom Preuzvišenošću, a potom Matoš i sam sebe proglašava mrtvim, dakle neškodljivim, i još k tomu izvan dosega ruke zakona. Ironičan je i kad, pišući o ljubavnoj aferi Geze Matačića i belgijske princeze, napiše da i „u Austriji ima srca-dabogme, ne pod carskim kaputom” (Književnici bez literature 1904; Matoš 1973b: 89). Austrija, dakako, srca nema za Hrvate.

Nasuprot, dakle, Matoševim izravnim političkim iskazima, u kojima se deklarira kao Hrvat starčevićanac (cf. O skidanju srpske zastave 1911; Matoš 1973c: 34), stoje jezične igre, lakrdije i travestije. Matoševa sklonost aforizmima i kalamburima očituje se u nizu primjera, kao kad ironično kaže Croatiae Croatae lupus (Bilježnica III 1901; Matoš 1973d: 265) - umjesto da izravno kaže da je Hrvatska pod austrijskom i mađarskom upravom negostoljubivo mjesto za Hrvate, radije parafrazira latinsku izreku. U svojim apologijama pravaštvu Matoš ne suspreže svoju kulturu: „Romantični zanos prije četrdesetosme pretvorio se u političku akciju bez jasnijeg hrvatskog obilježja. Rad Kvaternika i A. Starčevića pohrvati nolens-volens i pjesnike Jugoslavije" (Odjek s proslave Kola 1902; Matoš 1973b: 38-39). 
Nolens-volens u tom navodu nema sigurno nikakvu agitacijsku funkciju: tek mu je svrha pokazati rječitost autora. Rječitost Matoš tipično izražava brojnim metaforama, kao kad za književne kritičare kaže da su „književni paraziti, magarci koji žderu tuđe lavorike” (Nikad više! Feljton 1895; Matoš 1973b: 9) ili kad za idealnog pravaša kaže da je „sijač slobodne misli”, „desno krilo slobodnijih političara”, „desnica rodoljuba” i ,živa, vrela riječ koje ne može uništiti cenzura" (Pismo Aleksiju 1902; Matoš 1973b: 42).

Dojmu verbalnog obilja pridonose i brojni Matoševi epiteti, tipično grupirani u trijade (Pranjić 1991: 67). Primjerice, Matoš za jedan prijedlog kaže da je „đenijalan, jednostavan i koristan” (Nikad više! Feljton 1895; Matoš 1973b: 7), govori o „bečkoj, peštanskoj ili rimskoj tiraniji” (Čitaocu 1907; Matoš 1973a: 7) te prosvjeduje protiv ,podmuklih, masnih i žutih prstiju katoličkih popova”, ljut zbog ukidanja „Vienca”, za što okrivljuje ,popove i klerikalce" (Književnici bez literature 1904; Matoš 1973b: 87). Trijadni princip ne obuhvaća samo pridjeve, nego i imenice: Matoš „mrzi žabe, led i blato" (Impromtu. Op. II. Pismo iz Afrike 1904; Matoš 1973b: 22), a citirajući Dantona apelira na „smjelost, smjelost i opet smjelost” (Lijepa knjiga 1911; Matoš 1973c: 7).

Matošev antiklerikalizam svakako je povezan s njegovim liberalizmom i općenito promicanjem tekovina Francuske revolucije. Liberalizam „označava organizaciju društva koja dopušta i promiče slobodu i razvitak pojedinca" (Browning 2002: 219). Uz to, pojedince se smatra racionalnim bićima, a „njihova se vrijednost očituje u umnim sposobnostima da uređuju i oblikuju vlastite živote" (Browning 2002: 219). Da bi se pojedinca oslobodilo, nužno je proći kroz revoluciju koja „ruši stoljetne tiranije” i „drma apsolutizme”, unatoč tomu što stari režimi raspolažu s „milijun bajoneta” (Pismo Aleksiju 1902; Matoš 1973b: 43). Stekliško razočaranje cjelokupnim hrvatskim političkim životom Matoš inače neumorno i opetovano izriče, primjerice u članku Hrvati su došli prvotno tiskanome u „Slobodnoj reči” u Beogradu 1904.: „Političke stranke u Hrvatskoj su tako trule, tako kukavne, tako ropske, da je đak hrvatski, legendarni i veseli Grabancijaš, ostao kao jedini reprezentant političkog idealizma i zdrave narodne politike" (Matoš 1973b: 100). Lamentacija nad političkom truleži bila bi bez poente da ne postoje mladi. Mladi su tako, iz Matoševe vizure, revolucionarni element koji će se izboriti za nacionalnu državu, a potom, unutar tog okvira, i za liberalnu demokraciju - tako Matoš ohrabruje mlade na bavljenje 
politikom, umjesto da budu „literarno-novinarski snobovi” (Pismo Aleksiju 1902; Matoš 1973b: 43).

\section{Nacionalno i internacionalno}

Razjašnjavanju kompleksnog Matoševa pojma nacije Dubravka Oraić Tolić posvetila je opsežno poglavlje Matoš $i$ nacija u svojoj knjizi (2013: 251-330), a u njegovim publicističkim tekstovima ima obilje ilustracija stava da je pojam nacije neodvojiv od pojmova tradicije, kulture i slobode. Primjerice, tvrdi da je sloboda ,ideal”, „temeljna misao naše pjesme” i „divni zavjet slobodoljubivih otaca” (Odjek s proslave Kola 1902; Matoš 1973b: 38) te da su hrvatski jezik i povijest, osobito moderna, „najvažniji predmeti" za izobrazbu nove inteligencije, ali njihovo predavanje sprečavaju, nažalost, ,zli pastiri” (Ferije 1902; Matoš 1973b: 35). Dakle, da bi se slobodarske tradicije otaca uspješno prenijele mladim naraštajima, može se ili uroniti u narodno blago ili se pak obrazovati na modernim institucijama. A što ako ,zli pastiri” to onemogućavaju? Pa tradicija ima i za to recept: suvremeni pravaši moraju postati ,modernizovani nasljednici (...) uskoka i hajduka" (Pismo Aleksiju 1902; Matoš 1973b: 42). Krunoslav Pranjić u Matoševoj je umjetničkoj prozi našao brojne primjere „evokacije stila usmene predaje" (1971: 87), a lako ih je naći i u njegovim publicističkim tekstovima, primjerice: „Zulejka razrogači oči i ciknu, viknu «u po plača, u po smijeha»" (Impromtu. Op. II. Pismo iz Afrike 1904; Matoš 1973b: 22).

Čitanja Matoša već su otkrila brojna njegova proturječja, a na primjeru evokacije uskoka i hajduka dobro se vidi njihov mehanizam nastajanja. Naime, Matoš u raznorodnim pojavama - u navedenom slučaju u folkloru i sveučilištu - traži oslonac za svoju pravašku agitaciju. No ako jedna od tih pojava, poput sveučilišta pod stranim, nehrvatskim utjecajem, koči pravaški program, spreman je mobilizirati destruktivne sile iz druge pojave - uskoke i hajduke. Da Matoš doista nastoji pomiriti suprotne i suprotstavljene tendencije te da katkad nekoj povijesnoj pojavi pristupa iz jedne vizure, a katkad iz druge, razvidno je i na problemu odnosa Hrvata prema Židovima.

Ponajprije se valja sjetiti da Matoš počesto govori protiv stranih utjecaja u Hrvatskoj, pa npr. piše o ,iskorijenjenim, tuđinom rastresenim Hrvatima” (Odjek s proslave Kola 1902; Matoš 1973b: 39) - no sva je prilika da više 
misli na političku ovisnost o Pešti i Beču, nego na novu književnu modu iz Pariza koju i sam svesrdno uvozi. Na sličan način Matoš razvija dvostruke kriterije u pitanju antisemitizma. Iz pozicije hrvatskog tradicionalista Židov je stranac, dakle, netko tko ne može osjećati naciju i stoga je potencijalni neprijatelj; iz vizure modernosti, Židov je ravnopravni građanin. Primjerice, kada trgovac Jakob Weiss iz Kratečkog zaplijeni crkveno zvono zbog duga, Matoš piše sljedeće: „Ovaj slučaj u Kratečkom i opet jasno i glasno dokazuje kako židov, kao tuđinac, nema smisla ni za kakove naše narodne svetinje (Sudbina jednog seoskog zvona 1903; Matoš 1973b: 66). Istovremeno, polemizirajući s češkim piscem Vladislavom Šakom koji Josipa Franka, Matoševa stranačkog šefa, dezavuira zbog židovskog porijekla, iznosi sljedeće misli:

\begin{abstract}
Aludirajući, dalje, pan Schack na porijeklo dra Franka, izbacuje prostu izmišljotinu, dostojnu tek učenjaka za izvoz na Balkane. On, naime, tvrdi, vjeran slavosrpskom švindlovanju sa pojmovima pleme i narodnost, da se židovi svuda - kao Srbi u Hrvatskoj - osjećaju posebnim političkim narodom. To je, kako se vidi, sasvim plitka laž. Čuvajući svoje plemenske vrline, Židovi se svuda smatraju dijelom narodne cjeline gdje živu. U Francuskoj su dobri Francuzi, u Ugarskoj Mađari, u Poljskoj Poljaci. Pa i cionistički pokret, ukoliko postoji, ne ide za tim da (kao srpska propaganda u Hrvatskoj) nametne većini svoje ime kao narodno, ravnopravno i suvereno, ne nastoji politički istisnuti kao naseljenik svog narodnog suverena, već gleda dočepati se zemlje odakle se iselio (Pan Šak 1909; Matoš 1973b: 197-198).
\end{abstract}

U polemičkom žaru Matoš govori suprotno od onoga što je rekao o slučaju u Kratečkom: dok Weiss kao stranac nije i ne može biti lojalan, Frank može. Istovremeno, Matoš čini upravo ono što prigovara Šaku: opovrgavajući negativne stereotipe o Židovima, Matoš iskazuje vlastite o Nijemcima (Šakovo prezime piše njemačkom ortografijom Schack), Srbima (,slavosrpsko švindlovanje") i Balkancima općenito (Šak je bio bugarist koji je službovao u Sofiji, tj. tamo su ga ,izvezli”).

\title{
4. Hrvati, Srbi i Drugi
}

Navedeni ulomak otkriva još nešto: da židovsko pitanje uopće nije u Matoševu fokusu, nego su to hrvatsko-srpski odnosi. Matošu ne smeta odneseno crkveno zvono jer ionako o župniku misli da ima ,podmukle, masne 
i žute prste" (Književnici bez literature 1904; Matoš 1973b: 87), nego to što je Hrvatima nešto oteto. Isticanje židovske lojalnosti samo je pozadina na kojoj se može bolje uočiti sva nelojalnost Srba u Hrvatskoj - onako kako je vidi Stranka prava pod Frankovim vodstvom i s Matošem kao najelokventnijim članom.

Matošev odnos prema jugounitarizmu i Srbima vrlo je lijepo objasnila D. Oraić Tolić: ako Matoš govori o „Hrvatima jugoslavenskih, prosrpskih i jugounitarističkih uvjerenja”, to su onda ,polemički «Drugi»”, a Srbi su onda „kontrastni «Drugi»” (Oraić Tolić 2013: 257). Takva shema dopušta i malu dopunu: jugounitaristički Srbi ubrajali bi se u polemičke Druge, a gore navedeni opširni ulomak pokazuje baš takav odnos. Da za Matoša doista postoje Hrvati koji su politički Srbi te da postoje Srbi koji su svojevrsni izvorni neprijatelji, svjedoči sljedeći ulomak: „Takozvani realiste, opet, žrtvuju u svom vrludanju znak naše narodne suverenosti i misao hrvatstva, nemajući petlje da javno budu Srbi, dok Srbi traže slogu s nama pod pogodbom da oni dobiju sve, mi ništa" (Pismo iz Pariza 1903; Matoš 1973b: 73).

Istovremeno, postoji veliki niz tekstova u kojima Matoš vrlo afirmativno govori o Srbiji i Srbima, smatrajući ih jednostavno drugim narodom uz koji hrvatski može i mora samostalno i slobodno postojati. Primjerice, tekst $\mathrm{Od}$ Zagreba do Beograda (Fragmentarne impresije), objavljen 1906., Matoš je zaključio sljedećim riječima: „Beograd - jedva jedared! Kao iz ogromne tamnice dođoh u grad gdje sam slobodan i gdje i kralj govori bolje hrvatski od - mnogih hrvatskih ,patriota”. Pa ipak, pogiboh za gradom gdje najljepše na svijetu zvuči slatki kaj!" (Matoš 1967: 274). Matošev odnos prema naciji doista nije jednostavan: valja uočiti da je u tom ulomku Hrvatska tamnica, ali da unatoč tomu u srpskoj slobodi pati za „slatkim kajem”.

\section{Tijelo nacije}

Matoš je autor i ,najradikalnije inačice” toposa u kojem je nacija identificirana sa ženom (Rapacka 2002: 33) - misli se na sonet 1909. u kojem je Hrvatska prikazana u liku suhe obješene žene majčinskog lica. Prikazivanje domovine kao žene također je u literaturi već ocijenjeno kao „kombinacija esteticističko-impresionističke poetike i patriotske, pravaške retorike" (Coha 2012: 46). Pa dok je u tom sonetu slika patetična, Matoš tjelesnost 
nacije može zaodjenuti i u ironično ruho. Primjerice, u članku Radosti našeg ljeta - tiskanome 1903. u Trstu, izvan jurisdikcije omraženog bana Khuen-Héderváryja - Matoš piše o stjenici i o tome kako ona

pije krv, moju, tvoju, našu, vašu krv, dakle hrvatsku krv. (...) Kada je stjenica gladna i žedna, tanka je i mršava, kao Héderváryjev dolazak u Hrvatsku (...). A kada se naloče naše ustrpljive krvi hrvatske, onda ti se, moj brate, stjenica napuhne kao mješina, kao bačva, pusti ogroman trbuh i odšulja se, kao što je došla, u svoju tajanstvenu pradjedovsku kulu (Matoš 1973b: 60).

Stjenica je ovdje mađarski ban koji metaforički pije hrvatsku krv. Istu metaforu stjenice Matoš koristi i u Pismu iz Pariza, napisanu te iste godine, samo je u tom članku podrobnije razvijena metafora tijela čiju krv stjenica pije: „Tuđinac i Mađar piju mu krv, mađaron mu glođe obraz i poštenje, opozicija mu loče ono malo zdrave pameti, da narod postane prije smrti kretenom i idiotom!” (Matoš 1973b: 73). Nabrajajući i osuđujući razne političke aktere, Matoš ih uspoređuje s „otrovnim pečurkama” koje su se „rastićile na tom bolnom hrvatskom tijelu" (Matoš 1973b: 73).

Hrvatska država - ili hrvatski narod, barem kad se oduzmu od njega „polemički Drugi”, mađaroni, austrofili, jugounitaristi itd. - shvaća se kao tijelo, a njegov društveni boljitak jednak je tjelesnom zdravlju. Otrov, međutim, ne dolazi samo od gljiva (pasivnih), nego postoje i vrlo aktivni njegovi prenositelji:

Mi smo dosele mislili da Mađarska izvozi tek svoju horizontalnu kulturu, tisuće onih veselih i romantičnih stvorova koji već pomađariše sve trgovine ljudskim mesom od Pešte pa do Carigrada. Sada nas iznenađuje vijest da naše komšije ne izvoze samo razne pikantne Eržike, sentimentalne Rezike i Julčike koje nose u naše barbarske žile blagodati ugarskog sifilisa, nego da Ugarska izvozi i svoje profesore, svoju literaturu, svoju kulturu (Mađarska kultura 1904; Matoš 1973b: 107).

Strana je kultura, dakle, jednako tako otrovna za um kao i bacil sifilisa (koji izaziva teške duševne poremećaje kod bolesnika), a hrvatsko državno tijelo joj je, na pravašku žalost, otvoreno. Matoš je, međutim, i sam bio svjestan da se politička agitacija uspješnije posreduje čitateljima ako je izrečena jednostavnije, pa u istom članku ogoljuje mađarsku političku 
strategiju: „Mađarske težnje su očigledne (...). Danas je svakome jasno da Mađari teže na Jadransko more i sve što im je na putu, dakle Hrvatsku i Slavoniju, treba pregaziti, uništiti pauperizmom naroda, demoralizacijom inteligencije, i mađarizacijom" (Mađarska kultura 1904; Matoš 1973b: 108).

Budući da nacije identificira s tijelom, Matoš može političke odnose Hrvata i Mađara usporediti sa spolnim odnosima, primjerice sebe i sultanije Zulejke koja mu se obraća na sljedeći način: „O, edeš Gusti, odmah sam znao da si Mađar, jer samo Mađar-ember tako ljubi” (Impromtu. Op. II. Pismo iz Afrike 1904; Matoš 1973b: 22). I po mađarskim riječima koje Zulejka koristi, i po korištenju muškog roda da bi imenovala sebe (mađarski nema rodove pa je to tipična greška mađarskog govornika kada se služi hrvatskim), čitatelj shvaća da je sultanija personifikacija Mađarske, a nakon toga je razumljiva i Matoševa tužaljka zbog toga što ga ona želi ,zadaviti svojom prekodravskom ljubavlju" (Matoš 1973b: 22). Oksimoronska ljubav koja davi još je jedna snažna Matoševa figura koja na prenesen način ponavlja ono za što je kao uvjereni starčevićanac otvoreno agitirao.

\section{Zaključak}

Ideološke napetosti u Matoševim politički motiviranim tekstovima nastaju jer njegova poetika esteticizma stoji nasuprot političkoj pragmatici, internacionalno iskustvo bori se s uranjanjem u tradiciju, a poistovjećivanje s narodnim kolektivom teško se miri sa snažnim osjećajem individualnosti. $\mathrm{K}$ tomu, iako su ideologije najeksplicitnije i najartikuliranije u ,izravnom izražavanju značenja, znanja, mišljenja i raznih društvenih vjerovanja” (van Dijk 1998: 192), Matoš ih počesto upravo tako ne izražava, nego ih iskazuje u tekstovima koji rabe iste ili slične diskursne strategije poput njegovih eminentno literarnih radova.

A.G. Matoš dosljedno promiče pravašku politiku u svojim člancima, a to čini na dva načina: jedan je eksplicitan, a drugi figurativan. U eksplicitnom izražavanju nedvojbeno zastupa potrebu osnivanja hrvatske države koja bi bila neovisna i od Austrije, i od Mađarske, i od Srbije, a sve one Hrvate koji su spremni na kolaboraciju s neprijateljem smatra legitimnim objektima svojih polemičkih napada. 
Pravaški kulturološki performativ u njega je dobio konkretan umjetnički oblik i jednu novu energiju. On je potencijale pravaškoga radikalizma pretvorio ne samo u novi, moderni patriotizam nego i u osebujan i originalan stil koji je svoju potvrdu dobio u njegovim pjesničkim, polemičkim i satiričkim tekstovima (Nemec 2007: 129).

Ti se polemički napadi pak odlikuju brojnim stilskim osobinama koje dijele s Matoševim književnim radovima. Uz ironiju, Matoševi tekstovi koji promiču pravašku ideologiju sadrže brojne epitete, često složene u karakteristične trijade, i bogatu figurativnost. Glavne Matoševe tematske opreke očituju se u suprotnostima nacionalno-internacionalno, pojedinac-kolektiv, tradicija-modernost i Hrvati-Srbi, a to opet vodi do čestih proturječja. Naime, Matoš kao pobornik poetike esteticizma agitira za narodne tradicije; kao čovjek velikih međunarodnih iskustava, pledira za nacionalno; kao izraziti individualac, bori se za kolektiv; kao prijatelj Srba, suprotstavlja se njihovoj politici u Hrvatskoj.

Sva ta proturječja ocrtavaju Matošev politički imaginarij - pravaški ideal dân kroz vizuru umjetnika i intelektualca - čime se izbjegava jednostavna agitacija, a sve se političke poruke barem donekle relativiziraju. Naposljetku, i njegova konceptualna metafora Hrvatske kao tijela također je opterećena i estetskim i ideološkim proturječjima: istovremeno je dana i kao patetična slika majke, i kao ironična slika tijela koje hrani stjenicu, i kao antiestetička slika živog kadavera pomračena uma, i kao pragmatična slika tijela koje opći s drugim (državnim) tijelom - za što nalazi prikladni izričaj u oksimoronima, paradoksima i katahrezama koji spajaju nespojivo.

\section{Literatura}

Bagić K., 2012, Rječnik stilskih figura, Zagreb.

Browning G., 2002, Političke ideologije, u: Uvod u politologiju, prev. M. Paić Jurinić, ur. B. Axford et al. Zagreb, str. 213-248.

Coha S., 2012, Tko (ni)je 'spoznal' (n)i 'prepoznal' 'kipa domovine'? Od Štoosa preko Matoša prema Krleži, „Kaj - časopis za književnost, umjetnost, kulturu” br. 6, str. $25-52$.

van Dijk T.A., 1998, Ideology, London.

Jonjić T., 2012, Pogledi Antuna Gustava Matoša na hrvatsko-srpske odnose, „Pilar - časopis za društvene i humanističke studije" br. 13(1), str. 9-76. 
Matoš A.G., 1967, Kritike, eseji, studije i članci, polemike, putopisi, feljtoni i impresije, ur. D. Tadijanović, M. Matković, Zagreb.

Matoš A.G., 1973a, Sabrana djela, sv. 4, Vidici i putovi. Naši ljudi i krajevi, ur. D. Tadijanović, Zagreb.

Matoš A.G., 1973b, Sabrana djela, sv. 15, Feljtoni, impresije, članci I (1895-1910), ur. V. Flaker, Zagreb.

Matoš A.G., 1973c, Sabrana djela, sv. 16, Feljtoni, impresije, članci II (1911-1914), ur. V. Flaker, Zagreb.

Matoš A.G., 1973d, Sabrana djela, sv. 17, Bilježnice I-IV, ur. D. Kapetanić, Zagreb.

Nemec K., 2007, Pravaštvo i hrvatska književnost, u: Jezik književnosti i književni ideologemi, ur. K. Bagić, Zagreb, str. 119-129.

Oraić Tolić D., 2013, Čitanja Matoša, Zagreb.

Pranjić K., 1971, Jezik i stil Matoševe pripovjedačke proze, Zagreb.

Pranjić K., 1991, Jezikom i stilom kroza književnost, Zagreb.

Rapacka J., 2002, Leksikon hrvatskih tradicija, prev. D. Blažina, Zagreb.

Silić J., 2006, Funkcionalni stilovi hrvatskoga jezika, Zagreb. 
